\title{
Attractiveness, Trust and Trustworthiness: An Experimental Study
}

\author{
Kean-Siang Ch'ng ${ }^{\mathrm{a}}$ \\ Universiti Sains Malaysia
}

\begin{abstract}
Trust and reciprocating trust are two vital elements in any interpersonal relation. In a situation when there is no reputational information, people have been found to rely on physical cues, such as gender, race, attractiveness, facial expression and others to deduce trustworthiness of other parties. The present paper investigated this stereotype in a trust game by incorporating facial attractiveness. What we were interested in was the impact of attractiveness on trustors' trust on trustees and trustworthiness of the trustees. The main contribution of the paper is that it investigated the associations using a five-person trust game and allowed the trustors to evaluate the attractiveness of the trustee. The design allowed us to establish the causal association between individuals' perception on attractiveness and transfer more directly. The results showed male trustors ranked the same female trustees higher than female trustors in terms of attractiveness, and this was translated to higher transferred amount from male trustors to the trustees. Additionally, we find male trustors transferred significantly larger amount to more attractive female trustees than less attractive trustees, but there was no such difference among female trustors. However, the kindness extended by the male trustors to the more attractive female trustees were not reciprocated by the trustees. The trustworthiness as measured by the amount transferred back by trustees was not significantly different between less and more attractive trustees. The results highlighted systematic bias in decision making when prior information about the partners was not available.
\end{abstract}

Keywords: Attractiveness, experiment, trust, trust game, trustworthiness JEL classification: $\mathrm{C71}$, C91

\section{Introduction}

Trust is ubiquitous and vital in an interpersonal relationship. It involves trusting others and reciprocating that trust in any of our daily interactions. At firm level, trust has been found to be a morale booster to the employees; trust extended by the employers helps to improve the initiative and voluntary behaviours among employees (Dirks \& Ferrin, 2002; Konovsky \& Pugh, 1994), and at the macro level, trust has long been recorded and associated with social capital and better economic outcomes (Fukuyama, 1995; Knack \& Keefer, 1997). In many past behavioural studies, trust has been detected even

a Economics Department, School of Social Sciences, Universiti Sains Malaysia, 11800 USM, Penang, Malaysia. Email: cks@usm.my 
in a one-shot interaction. The absence of reputational information in a transaction between two strangers causes the parties to resort to more subtle information like the physical attributes to infer trustworthiness. The present paper investigated the role of attractiveness on trust and trustworthiness.

In experimental literature, much research has been conducted to measure trust and trustworthiness at an individual level. Trust is defined as one's willingness to be vulnerable based on expectation of cooperation from others (Rousseau et al., 1998). And trustworthiness is an altruistic behaviour of reciprocating trust (Ashraf et al., 2006). Trust and trustworthiness are tested and measured in the trust game experiment (Berg et al., 1995), and it has been widely reported in the literature about the long term stability of trust (Camerer, 2003). For example, in a research involving cross-country trust games, Yamagishi et al. (1998) and Hayashi et al. (1999) found consistently high level of trust between Japanese and US subjects. The stability of trust was also observed among strangers when the interaction was one shot (Eckel \& Wilson, 2004).

Another stream of research moved away from completely anonymous pairings of parties to limited information. This setup allows one to investigate whether trust is motivated by physical cues or attributes of the counterparties. This stream of research investigated the tendency to stereotype certain attributes when deciding to trust another person. In the papers by Scharlemann et al. (2001) and Eckel and Wilson (2003), they found that a simple gentle smile invited significantly more trust from trustors in a trust game experiment. In the same paper, trust was significantly higher when male trustors were matched with female trustees. And subjects with Caucasian origin did not trust the subjects from African-American origin. Similar results were also found in Burns (2003) between Blacks and Whites in South Africa and Fershtman and Gneezy (2001) among different ethnic groups in Israel. Our paper extends the existing literature by investigating the presence of beauty premium in the trust game. What interests us is the role of facial attractiveness on trust and reciprocity of trust.

Associating beauty to positive characteristics is ubiquitous in our daily life. Consciously or subconsciously, this stereotyping has influenced our decision making in any interaction with other parties. There is ample research proving the presence of beauty premium covering labour market, political science, education and many others, in which attractive people were given special privileges, such as higher salary (Biddle \& Hamermesh, 1998; Frieze et al., 1991), beautiful loan applicants were preferred (Ravina, 2012) and pretty sales personnel were preferred (Bruton, 2015; Rooth, 2009). This stereotyping is mainly due to people who tends to attribute attractiveness to positive characteristics, such as intelligence, competence and creativity to attractiveness. It suggests that attractiveness increases the probability that a person possesses positive traits and is more likely to succeed in social and economic interactions. In the present paper, we are interested to find the association between attractiveness and trust. It indirectly touches the question: are the attractive people really trustworthy?

In the literature about trust, attractive people are trusted more than less attractive counterparts. Attractive people were found to enjoy higher trust even if the interaction is one shot. In the paper by Wilson and Eckel (2006) for example, attractive trustees were viewed as more trustworthy than less attractive ones. A recent paper by Povoa 
et al. (2020) found that experimental subjects trusted women with facial makeup more than those without makeup. Smith et al. (2009) found that attractive subjects in a trust game trusted others more when told they were observed compared to when not observed. The present paper intends to not only investigate the association of attractiveness and trust but also the question: do the attractive ones reciprocate the trust? We built on past studies with some important modifications to the experimental design to investigate the two questions.

In the present paper, we tested the association of attractiveness, trust and trustworthiness in a one-shot trust game. Unlike previous papers (in which attractiveness were decided by an independent group of people), during the experiment, trustors were allowed to express their opinion about the attractiveness of the trustees on a Likert scale before they could decide on how much to transfer to the trustees. This experimental set up, enabled us to associate transfer amount and attractiveness more directly compared to when third party opinion was used. Built on the design in the paper by Smith et al. (2009), in our experiment, the trustees were not told that they were observed by the trustors. This was to ensure the trust reciprocated by the trustees was not influenced by other factors but purely by the altruistic behaviour to reciprocate. The design allowed us to determine the association between attractiveness and trust, and also attractiveness and reciprocity of the trustees.

We recruited undergraduate students from different cohorts to participate in the experiment. The results revealed that attractiveness is strongly associated with trust. Male trustors perceived the same female trustees to be significantly more attractive than female trustors; this translated to higher money transfer from male trustors than female trustors. When analysing the effect of attractiveness on trustworthiness, we find that attractive female trustees did not transfer different amounts of money compared to less attractive trustees. This means the attractiveness factor did not play any role in reciprocating the kindness extended by the trustors. Instead, the decision to transfer back was determined by the amount received by the trustees in the first round.

\section{Experimental Design}

We used the trust game introduced by Berg et al. (1995) to study trust and trustworthiness between strangers. The game consists of two groups with one group playing the role as trustors and another group as trustees. Each trustor is randomly matched with a trustee. The trustor receives an amount of money endowment (i.e. E) from experimenter and has to decide how much money to transfer (i.e. T) to the trustee. The endowment given to the trustor is common knowledge to both trustor and trustee. The experimenter triples the amount transferred (i.e. 3T) to the trustee and the amount that has not been transferred (i.e. E-T) remains with the trustor. The trustee then decides on how much to transfer back (i.e. TB) to the trustor from the tripled amount transferred by the trustor. The amount that is not transferred back to the trustor (i.e. 3T - TB) remains with the trustee. The final payoff to the trustor is equal to the amount not transferred to the trustee plus the amount transferred back from the trustee (i.e. $\mathrm{E}-\mathrm{T}+\mathrm{TB})$. The trustee's final payoff is equal to the tripled amount minus the amount trustee transferred back to the trustor (i.e. $3 T-T B$ ). The trust is measured by the 
amount transferred by the trustor to the trustee and trustworthiness is measured by the amount reciprocated or transferred back by the trustee.

We divided our study into two treatments. In the first treatment, two male trustors were matched randomly with one female trustee, and in the second treatment, two female trustors were matched with the same female trustee. The main reason for recruiting only female subjects as trustees is because many empirical proofs in past research showed significant gender differences in terms of perceiving and evaluating attractiveness. Instead of attractiveness, males emphasise more on financial standings, physical strength and social status when evaluating other male partners (Buss et al., 2000; Wiederman \& Allgeier., 1992). We undertook efforts to ensure trustors and trustees were from different cohorts or academic years in each matching so they did not know each other prior to the experiment. Each trustor was given an envelope that contained a photograph of the female trustee. Comparison between the first and second treatments allowed us to study the effect of gender.

There were 148 trustors and 37 trustees in the study. Each trustee was matched with 4 trustors ( 2 male and 2 female trustors). So in total we have 148 observations. The experiment was conducted first with male trustors and then followed by female trustors on the same day. All participants were undergraduate students from a local university. The trustees agreed to be photographed for use only in the experiment.

The participants were recruited via class announcements and word of mouth among the students. The recruitment was done separately for trustors and trustees to ensure both groups were from different academic years. They were told they were recruited to participate in an experiment but did not know the nature of the experiment. The experimenter read out the instruction on the procedures of the game during which the participants were allowed to ask any question. The briefing was done separately, first with the trustors and then with the trustees. When the experimenter was explaining the instructions to the trustors (trustees), trustees (trustors) waited in another room. When the briefings were over, they were ushered to the experimental lab, whereby they chose a computer terminal randomly and only the trustors received an envelope with photographs of the trustees. Each trustor was given an endowment of RM20. The trust game was programmed and conducted using experimental software z-Tree (Fischbacher, 2007).

When the experiment began, each trustor opened the envelope and indicated how attractive the person was in the photograph in a range from 1 - 10 (i.e. 10 being highly attractive). They then had to decide on how much to transfer to the trustee from the endowment. The amount transferred was tripled and the trustee had to decide how much to transfer back to the trustor. The final payoff to the trustors was calculated based on what was not transferred plus the amount transferred back by the trustee. The final payoff of the trustees was calculated based on the transferred amount times 3 minus the amount transferred back to the trustors. Since each trustee was matched with 4 trustors (i.e. 2 male and 2 female trustors), we randomly chose one final payoff as payment to the trustees.

We form our hypotheses as in the following:

Hypothesis 1: Male trustors give higher attractive score and consequently amount transferred than female trustors 
Hypothesis 2: Higher indicated attractiveness correlated with higher transfers from trustors.

Hypothesis 3: Higher transfer from trustors reciprocated with higher transfer back from trustees.

Hypothesis 4: Amount transferred back by highly attractive trustees is higher than less attractive trustees.

\section{Results}

Figure 1 shows the transfers of each level of indicated attractiveness according to male and female trustors. The Levene Test (Levene, 1960) reveals that the equality of variance across two factors, i.e. gender and attractiveness, cannot be rejected (F-value = $0.3972)$.

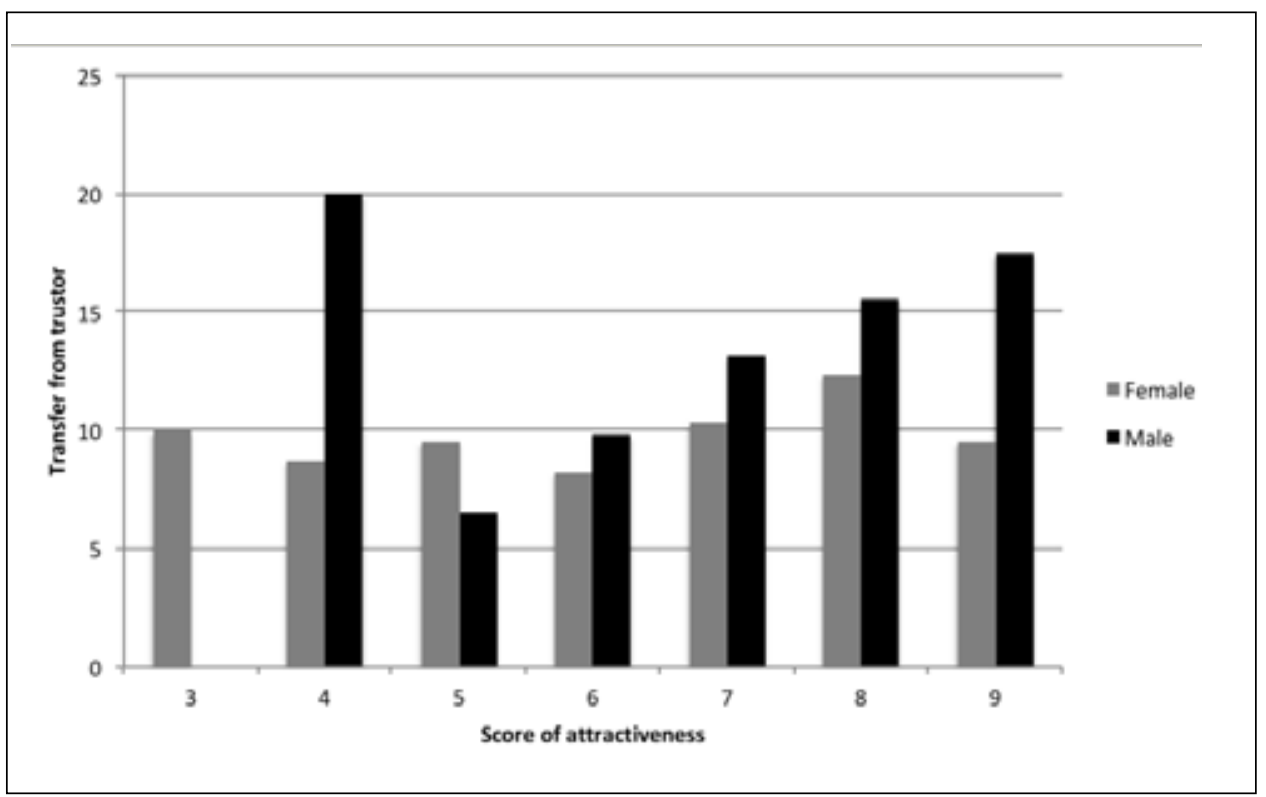

Figure 1. Transfers from trustors according to level of attractiveness

We first examine the perceived attractiveness indicated by male and female trustors. A group consisted of one trustee and 4 trustors. Recall that one trustee was matched with 4 trustors that consisted of 2 male and 2 female trustors. Figure 2 shows the attractiveness based on gender of the trustors from different groups. At first glance, we observe that male trustors gave higher attractiveness score than female trustors to the same female trustees. On average, male trustors gave significantly higher attractiveness score 7.06 than female trustors $6.40(F(1,135)=9.99$, prob $=$ 0.001). 


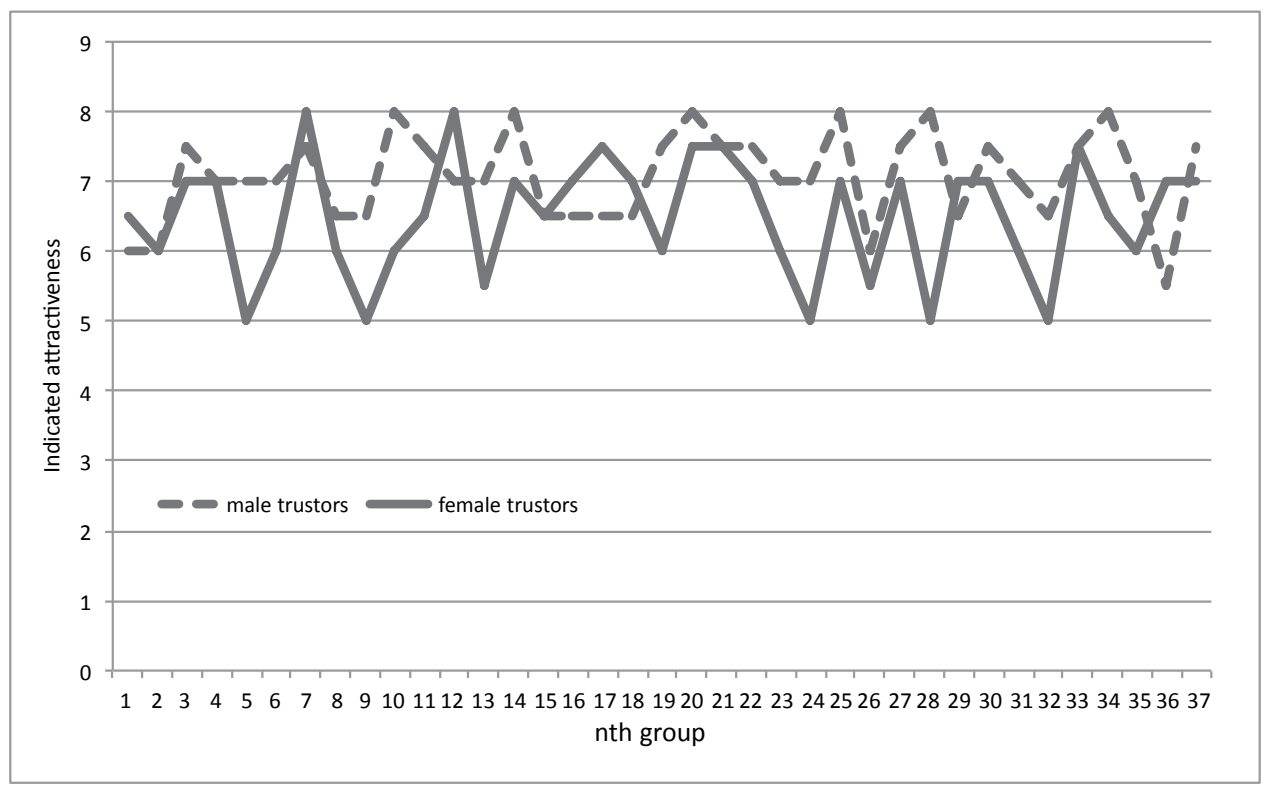

Figure 2. Indicated attractiveness by gender according to group

A similar analysis is used to investigate the association between indicated attractiveness and transfer from trustors to trustees. Figure 3 shows the relation between indicated attractiveness and transfers from trustors to trustees. A two-way ANOVA test reveals trustors who indicated high attractiveness score transferred significantly higher amount than those who gave lower attractiveness score $\left(\chi^{2}=836.39\right.$, prob $\left.=0.000\right)$.

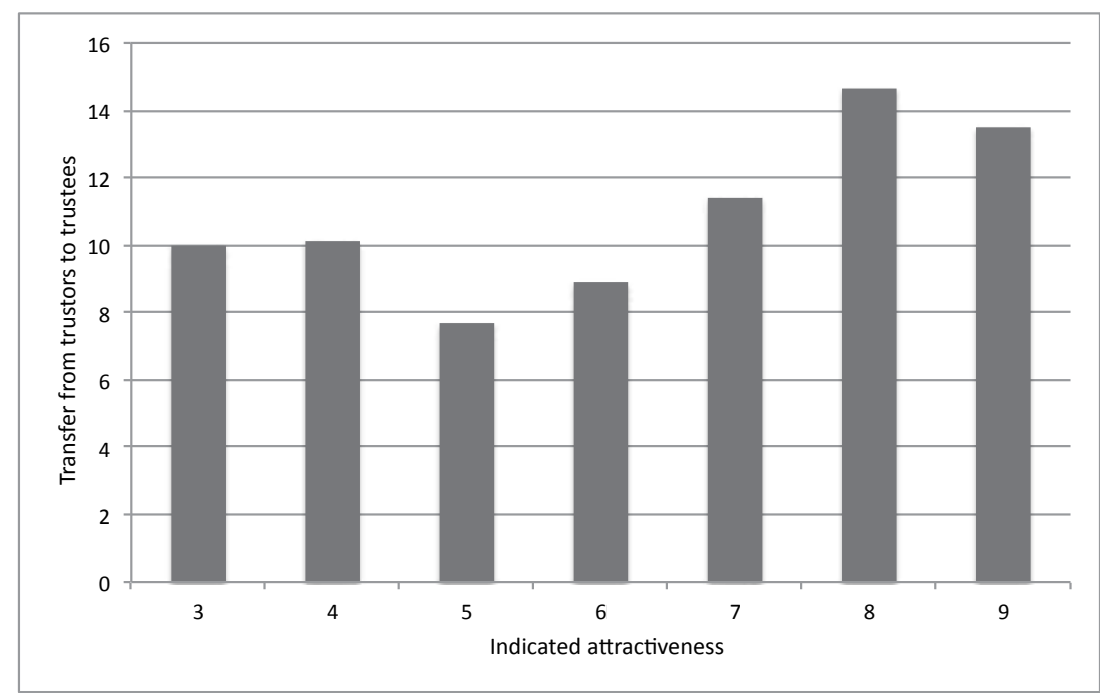

Figure 3. Average transfer based on indicated attractiveness 
Male trustors on average transferred significantly higher amount than female trustors to the same trustees. Figure 4 shows the difference of transferred amount from both genders; male trustors transferred, on average RM3 more than female trustors. The difference is statistically significant $\left(\chi^{2}=202.32\right.$, prob $\left.=0.000\right)$.

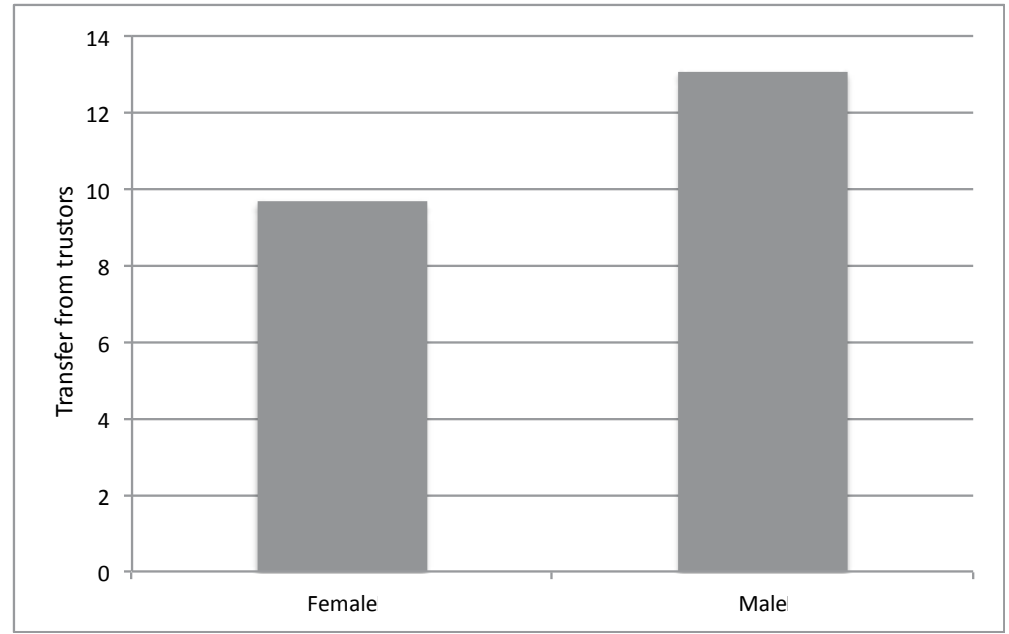

Figure 4. Average amount transferred according to gender of trustors

We next turn to examine if indicated attractiveness affects transfers made by male and female trustors. Figure 5 shows the amount of transfer for each level of indicated attractiveness by male and female trustors. A two-way ANOVA reveals a statistically

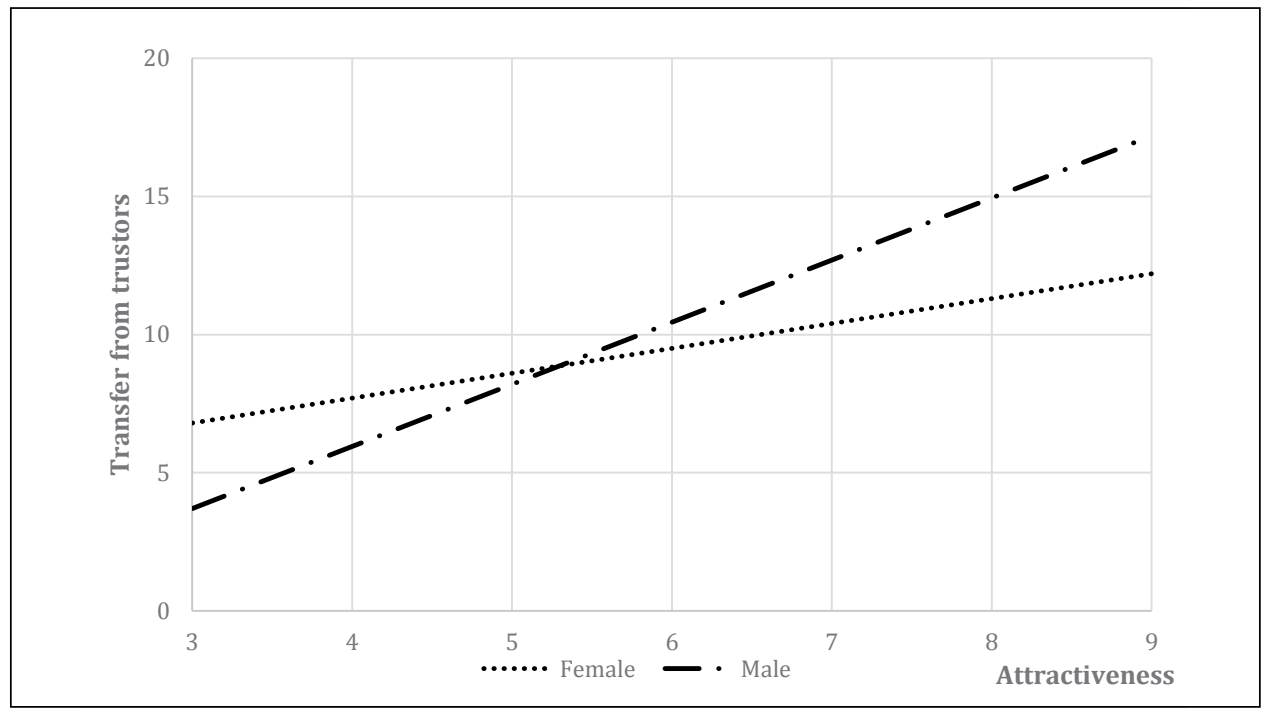

Figure 5. Amount of transfers made at each level of attractiveness by male and female trustors 
significant interaction effect between gender and attractiveness $(F(5,135)=3.34$, prob $=$ 0.000 ). Based on attractiveness level, the transferred amount was significantly different between male and female trustors; female trustors transferred significantly higher than male counterparts when attractiveness score was low (i.e. 3 to 4 attractiveness scores) $\left(\chi^{2}=16.5\right.$, prob $\left.=0.000\right)$ but when attractiveness score was above 5 , male trustors transferred significantly higher amount than female trustors $\left(\chi^{2}=24.08\right.$, prob $\left.=0.000\right)$. Only transfers from male trustors were significantly different between low attractive scores and high attractive scores $\left(\chi^{2}=95.60\right.$, prob $\left.=0.000\right)$; there is no statistical evidence to show female transferred significantly different amount between low and high attractiveness.

We can summarise that when giving attractive scores to the trustees, male trustors gave significantly higher attractive scores than female trustors. The high attractive scores corresponded to the amount of transfers made by the trustors; on average male trustors transferred higher amount than female trustors to the same trustees. The pattern conforms to our first three hypotheses.

We next turn to investigate the last hypothesis, namely did the trustees reciprocate the amount transferred from the trustors or the trustworthiness of the trustees. We run a simple OLS regression with "attractiveness" as categorical and "transfer" as continuous independent variables and "transfer back" from trustees as dependent variable. Table 1 reports the result of the regression with three different models. Models 1 and 2 regress "transfer" and "attractiveness" on dependent variable "transfer back" separately, while model 3 combines the two independent variables in a single regression. The regression results reveal that transfer back from trustees is significantly dependent on the transfer from trustors, meaning the trustees reciprocated the amount transferred by the trustors. Figure 6 shows that the returned amounts by the trustees are closely related to the amount transferred from the trustors. Based on the regression

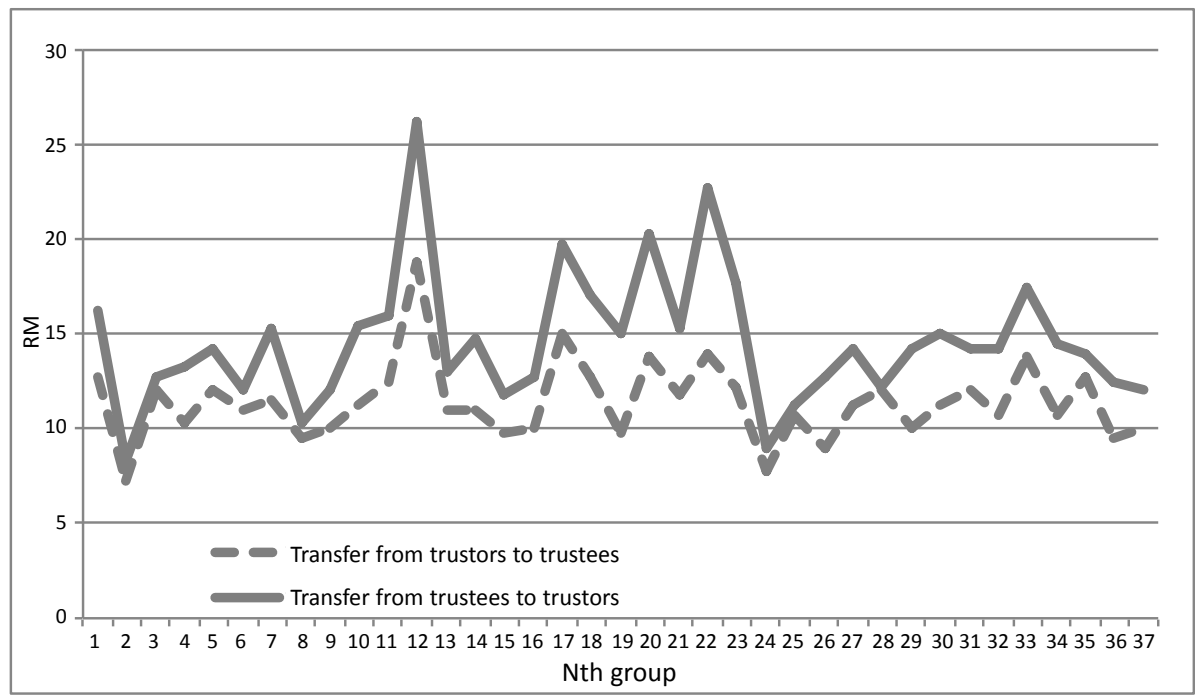

Figure 6. Correlation between transfers from trustors and trustees 
Table 1. OLS regression on transfer back from trustees

\begin{tabular}{|c|c|c|c|}
\hline \multirow[b]{2}{*}{ Model } & \multicolumn{3}{|c|}{ Transfer back } \\
\hline & 1 & 2 & 3 \\
\hline Constant & $\begin{array}{l}0.8511 \\
(1.04)\end{array}$ & $\begin{array}{c}15.0000^{* *} \\
(2.46)\end{array}$ & $\begin{array}{l}4.9270 \\
(1.08)\end{array}$ \\
\hline Transfer & $\begin{array}{l}1.2065^{* * *} \\
(18.08)\end{array}$ & & $\begin{array}{c}1.0072^{* * *} \\
(3.86)\end{array}$ \\
\hline \multicolumn{4}{|c|}{ Attractiveness } \\
\hline 4 & & $\begin{array}{c}-2.1250 \\
(-0.33)\end{array}$ & $\begin{array}{c}-4.6346 \\
(-0.80)\end{array}$ \\
\hline 5 & & $\begin{array}{c}-4.5000 \\
(-0.70)\end{array}$ & $\begin{array}{c}-8.5021 \\
(-1.58)\end{array}$ \\
\hline 6 & & $\begin{array}{c}-3.6818 \\
(-0.60)\end{array}$ & $\begin{array}{c}-5.4470 \\
(-1.13)\end{array}$ \\
\hline 7 & & $\begin{array}{l}0.3235 \\
(0.05)\end{array}$ & $\begin{array}{c}-4.2306 \\
(-0.84)\end{array}$ \\
\hline 8 & & $\begin{array}{c}3.0930 \\
(0.50)\end{array}$ & $\begin{array}{c}-2.3058 \\
(-0.46)\end{array}$ \\
\hline 9 & & $\begin{array}{l}2.3750 \\
(0.37)\end{array}$ & $\begin{array}{c}-1.1504 \\
(-0.28)\end{array}$ \\
\hline \multicolumn{4}{|c|}{ Attractiveness\#transfer } \\
\hline 4 & & & $\begin{array}{c}0.2354 \\
(0.57)\end{array}$ \\
\hline 5 & & & $\begin{array}{c}0.8206^{*} \\
(1.94)\end{array}$ \\
\hline 6 & & & $\begin{array}{c}0.3248 \\
(1.06)\end{array}$ \\
\hline 7 & & & $\begin{array}{l}0.2744 \\
(0.88)\end{array}$ \\
\hline 8 & & & $\begin{array}{l}0.0487 \\
(0.16)\end{array}$ \\
\hline 9 & & & - \\
\hline $\mathrm{n}$ & 148 & 148 & 148 \\
\hline R-squared & 0.68 & 0.19 & 0.70 \\
\hline
\end{tabular}

Note: $*, * *, * * *$ denotes $10 \%, 5 \%$ and $1 \%$ significance level. Numbers in parentheses are t-statistics. Transfer back means amount transferred from trustees to trustors. Transfer denotes transfer amount from trustors to trustees. Attractiveness \# transfer denotes attractiveness interacts with transfer. The results compared attractiveness levels with benchmark level at 3 . 
result in Table 1, for every RM1 transferred by trustors, trustees reciprocated with RM1.2065 (t-statistics $=18.08$, prob $=0.000$ ).

On the attractiveness and transfer back, however, we do not observe any significant differences in transfer back amount according to attractiveness. Meaning highly attractive trustees as indicated by the trustors, did not behave differently compared to less attractive trustees when transferring amount back to the trustors. Pairwise comparison taking attractiveness level 3 as benchmark, reveals that amount of transfer back does not differ significantly across all attractiveness levels $(F(6,135)=1.19$, prob $=0.3187)$.

\section{Discussion and Conclusion}

The present paper investigated role of attractiveness, trust and trustworthiness between strangers in a one-shot trust game. Trust was measured by the amount of money transferred from the trustors to the trustees, and trustworthiness was measured by the amount transferred back from the trustees to the trustors. The participants of the experiment were undergraduate students and were recruited from different cohorts. It was to ensure they did not know each other prior to the experiment. The trustors were given a photograph and asked to rate the attractiveness of the trustee before deciding on how much to transfer to the trustees. The setup ensured that the only attribute they knew was the facial appearance of the trustees.

We formed 37 groups, each group consisted of two male and two female trustors matched with a female trustee. In total there were 148 trustors and 37 trustees. After indicating the attractiveness level of the trustees on a Likert scale from 1 to 10, the trustors then had to decide how much to transfer to the trustees from a given endowment. The amount transferred then was tripled by the experimenter. After observing how much they received from the trustors, the trustees then had to decide how much to transfer back to the trustors. We intend to study the effect of gender on perceived attractiveness and on the amount transferred to the trustees, the effect of attractiveness on the amount transferred (i.e. trust) and on the amount transferred back from the trustees (i.e. trustworthiness).

Using the same female trustees who were matched with 2 male and 2 female trustors, allowed us to examine the effect of gender on perceived attractiveness and amount of transfer. The result reveals that male trustors, on average, gave significantly higher attractive score than female trustors on the same female trustee. This difference may be due to female's jealousy or feeling threatened by the attractiveness of other females. The result conforms to the findings from previous research. It has been widely researched in the past field studies that there were significant differences between male and female respondents when asked to rate the attractiveness of other females. Mileva et al. (2016) found that women rated other attractive women with facial cosmetics as more dominant and more promiscuous compared to men raters who perceived the same women as more prestigious. In the paper by Buss et al. (2000), women were reported to show more jealousy towards physically attractive women than less physically attractive women, feeling threatened by the presence of more feminine women (Fink et al., 2014). This is because women feel threatened by the dominance of other women due to their beauty and attractiveness (Walkins et al., 2012). 
Consistent with the "beauty premium" literature (Hamermesh, 2011), we also find strong association between indicated attractiveness and amount transferred to the trustees. The result reveals that trustors who gave higher attractive scores transferred larger amount to the trustees compared to those who gave lower attractive scores. Our result is consistent with other research done in an experimental setup that showed attractiveness matters in a decision that required trust (Wilson \& Eckel, 2006; Povoa et al., 2020).

To measure trustworthiness of the trustees, we looked into the relation between amount transferred back by trustees and their attractiveness, and amount transferred to them (i.e., trust). Our result shows the transfers from the trustors were reciprocated by the trustees due to the amount transferred but not because of the level of attractiveness. On average, transferred amount was 56\% from the endowment, which is very near to the amount transferred recorded in past literature that studied trust games among strangers. The amount the trustees reciprocated by transferring back to trustors was correlated to the amount initially transferred by the trustors (Camerer, 2003; Eckel \& Wilson, 2004; Yamagishi et al., 1998). Although the interaction was mediated by the factor attractiveness, the behaviour to reciprocate trust did not change; decision to reciprocate did not differ between more attractive and less attractive trustees. Our last result was similarly reported in Wilson and Eckel (2006) and Andreoni and Petrie (2004).

The results in the present paper highlight an important role of systematic bias in a strategic choice. Much of the past research has focused on cognitive constraints and the way in which perceptual biases enter into decision-making process (Camerer, 1997; Loewenstein, 2000; Loewenstein et al., 2003). Our findings suggest that, in contrast to standard models of decision-making process, a stereotype such as attributing attractiveness as more trustworthy is vital in a strategic interaction when there was no prior interaction. The human ability to make rapid judgment based on stereotype can be construed, as an act to economise on deliberate analysis when searching for more information is costly.

\section{References}

Andreoni, J., \& Petrie, R. (2004). Public goods experiment without confidentiality: A glimpse into fund raising. Journal of Public Economics, 88(7-8), 1605-1623. https://doi.org/10.1016/ S0047-2727(03)00040-9

Ashraf, N., Bohnet, l., \& Piankov, N. (2006). Decomposing trust and trustworthiness. Experimental Economics, 9(3), 193-208. https://doi.org/10.1007/s10683-006-9122-4

Berg, J., Dickhaut, J., \& McCabe, K. (1995). Trust, reciprocity and social history. Games and Economic Behavior, 10(1), 122-142. https://doi.org/10.1006/game.1995.1027

Biddle, J.E., \& Hamermesh, D.S. (1998). Beauty, productivity, and discrimination: Lawyers' looks and lucre. Journal of Labor Economics, 16(1), 172-201.

Bruton, S.V. (2015). Looks-based hiring and wrongful discrimination. Business and Society Review, 120(4), 607-635. https://doi.org/10.1111/basr.12076

Burns, J. (2003). Insider-outsider distinctions in South Africa: The impact of race on the behavior of high school students. Paper presented at the Conference on Field Experiments, Middlebury College, Middlebury. 
Buss, D.M., Shackelford, T.K., Choe, J., Buunk, B.P., \& Dijkstra, P. (2000). Distress about mating rivals. Personal Relationships, 7(3), 235-243. https://doi.org/10.1111/j.1475-6811.2000. tb00014.x

Camerer, C. (1997). Progress in behavioral game theory. Journal of Economic Perspectives, 11(4), 167-188. DOI: 10.1257/jep.11.4.167

Camerer, C. (2003). Behavioral game theory: Experiments in strategic interaction. Russell Sage Foundation and Princeton University Press.

Dirks, K.T., \& Ferrin, D.L. (2002). Tust in leadership: Meta-analytic findings and implications for research and practice. Journal of Applied Psychology, 87(4), 611-628. https://doi. org/10.1037/0021-9010.87.4.611

Eckel, C.C., \& Wilson, R.K. (2003). Conditional trust: Sex, race and facial expressions in a trust game. Paper presented at the Conference on Trust and Institutions, Harvard University.

Eckel, C.C., \& Wilson, R.K. (2004). Is trust a risky decision? Journal of Economic Behavior \& Organization, 55(4), 447-465. https://doi.org/10.1016/j.jebo.2003.11.003

Fershtman, C., \& Gneezy, U. (2001). Discrimination in a segmented society: An experimental approach. Quarterly Journal of Economics, 116(1), 351-377. https://doi.org/10.1162/ 003355301556338

Fink, B., Klappauf, D., Brewer, G., \& Shackelford, T.K. (2014). Female physical characteristics and intra-sexual competition in women. Personality and Individual Differences, 58(February), 138-141. https://doi.org/10.1007/978-3-319-16999-6_1424-1

Fischbacher, U. (2007). z-Tree: Zurich toolbox for ready made economic experiments. Experimental Economics, 10, 171-178. https://doi.org/10.1007/s10683-006-9159-4

Frieze, I.H., Olson, J.E., \& Russel, J. (1991). Attractiveness and income for men and women in management. Journal of Applied Social Psychology, 21(13), 1039-1057. https://doi. org/10.1111/j.1559-1816.1991.tb00458.x

Fukuyama, F. (1995). Trust: The social virtues and the creation of prosperity. Free Press.

Hamermesh, D.S. (2011). Beauty pays: Why attractive people are more successful. Princeton University Press.

Hayashi, N., Ostrom, E., Walker, J., \& Yamagishi, T. (1999). Reciprocity, trust and the sense of control: A cross-societal study. Rationality and Society, 11(1), 27-46. https://doi. org $/ 10.1177 / 104346399011001002$

Knack, S., \& Keefer, P. (1997). Does social capital have an economic payoff? A cross-country investigation. Quarterly Journal of Economics, 112(4), 1251-1288. https://doi.org/10.1162/ 003355300555475

Konovsky, M.A., \& Pugh, S.D. (1994). Citizenship behavioral and social exchange. Academy of Management Journal, 37(3), 656-669. https://doi.org/10.5465/256704

Levene, H. (1960). Contributions to probability and statistics: Essays in honor of Harod Hotelling. Stanford University Press.

Loewenstein, G. (2000). Emotions in economic theory and economic behavior. American Economic Review, 90(2), 426-432. https://doi.org/10.1257/aer.90.2.426

Loewenstein, G., O'Donoghue, T., \& Rabin, M. (2003). Projection bias in predicting future utility. Quarterly Journal of Economics, 118(4), 1209-1248. https://doi.org/10.1162/003355 303322552784

Mileva, V.R., Jones, A.L., Russel, R., \& Little, A.C. (2016). Sex differences in the perceived dominance and prestige of women with and without cosmetics. Perception, 45(10), 11661183. https://doi.org/10.1177/0301006616652053

Povoa, A.C.S., Pech, W., Viacava, J.J.C., \& Schwartz, M.T. (2020). Is the beauty premium accessible to all? An experimental analysis. Journal of Economic Psychology, 78(June), 1-12. https://doi. org/10.1016/j.joep.2020.102252 
Ravina, E. (2012). Love and loans: The effect of beauty and personal characteristics in credit markets. SSRN Electronic Journal, 1-66. https://doi.org/10.2139/ssrn.1101647

Rooth, D.-O. (2009). Obesity, attractiveness, and differential treatment in hiring: A field experiment. The Journal of Human Resources, 44(3), 710-735. https://doi.org/10.3368/jhr.44.3.710

Rousseau, D.M., Sitkin, S.B., Burt, R.S., \& Camerer, C. (1998). Not so different after all: A cross discipline view of trust. Academy of Management Review, 23(3), 393-404. https://doi. org/10.5465/amr.1998.926617

Scharlemann, J.P., Eckel, C.C., Kacelnik, A., \& Wilson, R.K. (2001). Value of smile: Game theory with a human face. Journal of Economic Psychology, 22(5), 617-640. https://doi.org/10.1016/ S0167-4870(01)00059-9

Smith, F.G., Debruine, L.M., Jones, B.C., Krupp, D.B., Welling, L.L.M., \& Conway, C.A. (2009). Attractiveness qualifies the effect of observation on trusting behavior in an economic game. Evolution and Human Behavior, 30(6), 393-397. https://doi.org/10.1016/j.evolhumbehav. 2009.06.003

Walkins, C.D., Quist, M.C., Smith, F.G., Debruine, L.M., \& Jones, B.C. (2012). Individual differences in women's perceptions of other women's dominance. European Journal of Personality, 26(1), 79-86. https://doi.org/10.1002/per.837

Wiederman, M.W., \& Allgeier, E.R. (1992). Gender differences in mate selection criteria: Sociobiological or socioeconomic explanation? Ethology and Sociobiology, 13(2), 115-124. https:// doi.org/https://doi.org/10.1016/0162-3095(92)90021-U

Wilson, R.K., \& Eckel, C.C. (2006). Judging a book by its cover: Beauty and expectations in a trust game. Political Research Quarterly, 59(2), 189-202. https://doi.org/10.1177/ 106591290605900202

Yamagishi, T., Cook, K.S.., \& Watabe, M. (1998). Uncertainty, trust and commitment formation in the United States and Japan. American Journal of Sociology, 104(1), 165-194. https://doi. org/10.1086/210005 
